\title{
Extensão Universitária na Graduação em Nutrição: Experiências de Produção de Vídeos Educativos
}

\author{
Felipe Daun*1 e Ana Maria Dianezi Gambardella² \\ 1Programa de Pós-graduação Nutrição em Saúde Pública, ${ }^{2}$ Departamento de Nutrição \\ Faculdade de Saúde Pública da Universidade de São Paulo
}

* Autor para correspondência: felipedaun@yahoo.com.br

\section{RESUMO}

Por iniciativa de alunos de graduação, foi criado o projeto USParódia, que desenvolve vídeos sobre educação nutricional e promoção da saúde dirigidos à população jovem. $\mathrm{O}$ presente trabalho se propõe a avaliar o desempenho dessa iniciativa e a contribuição dela para a formação dos graduandos em Nutrição. Toda a manutenção do USParódia foi atribuída aos alunos, que realizaram pesquisa na literatura científica, criaram mensagens educativas, elaboraram os roteiros, gravaram os vídeos e os divulgaram na internet. A fim de avaliar qualitativamente o aproveitamento dos discentes no projeto, foram realizadas quatro entrevistas individuais com alguns deles. Entre novembro de 2013 e março de 2016 foram produzidos 23 vídeos, abordando diversos temas sobre nutrição e saúde de maneira simples e comunicativa. Os vídeos alcançaram aproximadamente oitenta mil visualizações nesse período e apresentaram boa aceitabilidade nas redes sociais. Verificou-se que o projeto contribuiu para a ampliação da formação discente, apresentando novas ferramentas e abordagens de comunicação e didática. O estudo mostrou que o USParódia revelou-se enriquecedor bilateralmente, pois além da promoção da saúde na internet, contribuiu para a formação de seus integrantes.

Palavras-chave: Educação Nutricional; Educomunicação; Promoção da Saúde; Vídeo; Internet.

\begin{abstract}
Graduate students created the project USParódia to develop videos on the Internet, targeted at young people about nutrition education and health promotion. The aim of this study was to evaluate the performance and contribution of the project for the academic background in Nutrition. The students were responsible to all maintenance of the project, who conducted research in the scientific literature, creation of educational messages, writing scripts, recording of the video and its dissemination on the Internet. The qualitatively assess of student performance were four individual interviews. Between November 2013 and March 201623 videos were produced, covering various topics on nutrition and health with a simple and communicative manner. The videos reached almost eighty thousand views in this period, and showed good acceptability in social networks. The project contributed to the expansion of the academic background, with new tools and teaching and communication approaches. The study showed that USParódia project was enriching bilaterally, because besides the health promotion on the Internet has contributed to the formation of its members.
\end{abstract}

Keywords: Nutrition Education; Educommunication; Health Promotion; Video; Internet.

\section{Introdução}

Os últimos anos foram marcados pela afirmação da internet na sociedade, processo que possibilitou o desenvolvimento de novas tecnologias que alteraram o cenário da educação em saúde. Na esfera da nutrição, observa-se a criação de novas áreas de atuação e o aprimoramento de outras. Porém, a maioria dos egressos, ainda, são direcionados para as áreas de nutrição clínica e alimentação coletiva (LOBO, 2015; RECINE et al., 2012).

A Faculdade de Saúde Pública da Universidade de São Paulo, em virtude da recente alteração curricular de seu curso de graduação em Nutrição, propõe a ampliação da atuação do futuro profissional e se diferencia de outras faculdades ao visar mais à importância da nutrição como promotora de saúde do que como curadora de doen- 
ças. Dentre as disciplinas do currículo destaca-se Educação Nutricional, em que os alunos são incentivados a praticar a promoção da saúde de maneira inovadora e atrativa. Nesse contexto, durante o percurso de tal disciplina, um grupo de alunos teve a iniciativa de criar um projeto de extensão universitária dirigido à promoção da saúde para jovens por meio de vídeos divulgados na internet.

$\mathrm{O}$ vídeo pode ser entendido como uma ferramenta capaz de transferir o cotidiano para o momento do processo educativo, permitindo o emprego de novas linguagens e viabilizando uma abordagem alternativa à educação convencional (BOOG et al., 2003). Nesse cenário se encontra o YouTube, uma plataforma de compartilhamento de vídeos que alcança mais de oitocentos milhões de pessoas, e que se mostra como um promissor instrumento para a educação e a comunicação em saúde (DUNCAN et al., 2012; ABEDIN et al., 2015).

Os processos envolvidos na criação do USParódia possibilitam aos alunos a exploração de novas ferramentas e a aquisição de novas habilidades e aptidões, expandindo a sua formação durante a graduação. O objetivo do presente estudo foi avaliar o desempenho da produção de vídeos educativos como projeto de extensão universitária e a sua contribuição para a formação dos graduandos em Nutrição.

\section{Desenvolvimento}

\section{Métodos}

A idealização do projeto, como um canal na plataforma YouTube, partiu da iniciativa de um grupo de alunos de graduação em Nutrição em novembro de 2013. Estruturou-se a produção de vídeos de maneira que toda a responsabilidade pela produção e pelo conteúdo, de periodicidade mensal, fosse dos graduandos. A característica comum dos vídeos é a apresentação de uma paródia musical, que acabou por dar origem ao nome USParódia. O projeto vinculou-se ao programa Aprender com Gultura e Extensão em 2014, no qual permanece até o momento da confecção do presente trabalho. O referido programa ofereceu duas bolsas para que os alunos de graduação (selecionados segundo critérios de classificação socioeconômica, seguida de entrevista) desenvolverem as atividades inicialmente proposta.

As atividades dos alunos compreendem toda a manutenção do projeto. O cronograma de produção foi desenhado para que fosse finalizado um vídeo por mês. $\mathrm{O}$ uso de melodias de terceiros para a produção de paródias musicais é permitido em conformidade com as políticas de direitos autorais do YouTube, sendo este a plataforma exclusiva de carregamento dos vídeos.

Apesar do cunho humorístico do modelo adotado, os vídeos foram planejados com embasamento na literatura científica de modo a transmitirem uma mensagem educacional. Esta é definida pelos próprios alunos de graduação após levantamento de temas relevantes e de artigos científicos sobre os assuntos a serem abordados. Estabelecida a mensagem, os estudantes selecionam a música, escrevem a paródia e roteirizam o vídeo. As filmagens ocorrem nas dependências da Faculdade de Saúde Pública (FSP), no estúdio de Tecnologia da Informação e Comunicação da FSP, em locais públicos e nas residências dos próprios graduandos. Os vídeos são editados no laboratório de informática da Faculdade de Saúde Pública, mediante o emprego, sobretudo, dos softwares Wavesaur, Microsoft Power Point e Windows Movie Maker.

Os vídeos são carregados na plataforma YouTube e divulgados nas redes sociais Facebook, Twitter e Instagram. A análise de amplitude, retenção do público, perfil dos usuários e número de visualizações dos vídeos é realizada pela ferramenta YouTube Analytics. A média de tempo de visualização de cada vídeo carregado é realizada pela análise de retenção de público, por meio da qual se é possível verificar se a mensagem educativa alcançou o usuário.

Para a avaliação do aproveitamento dos alunos de graduação realizaram-se entrevistas individuais de resposta aberta em que foram questionados os desafios do desenvolvimento do 
projeto, a influência dele na graduação e seu impacto na formação dos discentes envolvidos. Os relatos dos alunos foram transcritos e analisados quanto ao conteúdo, o que permitiu identificar e agrupar tais documentos (GOMES et al., 2005).

\section{Resultados e Discussões}

No período considerado (novembro de 2013 a março de 2016) foram produzidos 23 vídeos (para informações sobre alguns deles, vide Anexo 1), seguindo a seguinte divisão: os quatro primeiros, feitos em 2013, foram produzidos, de maneira independente, pelos idealizadores do projeto; os doze vídeos seguintes foram realizados pelos bolsistas do Programa Aprender com Cultura e Extensão do período 2014-2015, e a produção dos últimos sete coube aos bolsistas do período de 2015-2016.

Os temas abordados foram: consumo de frutas; dietas da moda; dietas em feriados comemorativos; consumo de hortaliças; anorexia e bulimia; controle do diabetes; gorduras trans; anemia; constipação; hidratação; imagem do nutricionista; consumo de chocolate; o Novo Guia Alimentar para a População Brasileira; higiene e comida de rua; hábitos de cozinhar; consumo de alimentos ultraprocessados; conhecimento sobre alimentos ultraprocessados; néctares e preparados para refresco em pó; retomada de tradições na cozinha; aperitivos industrializados; bebidas adoçadas; shakes emagrecedores; sopas instantâneas.

O conjunto de todos os vídeos atingiu a marca de 79.487 visualizações até o final do mês de março de 2016. Os vídeos são assistidos no mínimo até $50 \%$ do tempo total de duração, o que já se mostra suficiente para a transmissão da mensagem educativa. O canal do YouTube possui 284 inscritos, ou seja, usuários interessados em receber os próximos vídeos, bem como 520 "curtidas" no Facebook, 146 seguidores no Twitter e 119 seguidores no Instagram. O público é predominantemente feminino (69\%), em sua maioria na faixa dos 19 aos 24 anos. Metade da origem de tráfego, ou seja, da maneira como os usuários chegam aos vídeos, ocorre por sugestões automáticas do YouTube. O alcance em 24 horas das publicações dos vídeos no Facebook é de 800 usuários (valor médio) para cada vídeo publicado.

Foram entrevistados quatro alunos vinculados ao projeto, e foi possível agrupar os seguintes consensos: a participação no projeto estimula a criatividade e a didática; incentiva a busca por informação científica e maneiras de traduzi-las para a população; instiga o uso de novas plataformas de vinculação de conhecimento, como as ferramentas de edição de vídeo; proporciona entendimento sobre o funcionamento das mecânicas das redes sociais e de compartilhamento de vídeos.

A realização dos vídeos envolve um complexo processo no qual os alunos aprimoram as habilidades adquiridas no transcorrer da graduação e também desenvolvem novas aptidões não oferecidas durante o curso. O procedimento para a produção dos vídeos induz o aluno a realizar pesquisa exaustiva na literatura científica, e aperfeiçoa essa competência durante sua graduação. A busca por mensagens persuasivas estimula a capacidade de síntese e adequação à linguagem popular, para que os vídeos tenham significado para o público. As letras das paródias, assim como os roteiros dos vídeos, estimulam a criatividade e melhoram a comunicação e a didática, como se observa nas falas dos estudantes:

Tivemos diversos desafios, dentre eles [...] exercitar a criatividade para que em todos os meses fosse postada uma ideia diferente e que ao mesmo tempo fosse interessante, [...] para que a mensagem seja passada ao maior número de pessoas.

[...] as apresentações dos trabalhos acadêmicos também ficaram mais fáceis, pois requerem didática, como na elaboração dos vídeos.

Considerando-se o cunho de desenvolvimento científico, a Universidade de São Paulo representa um grande nicho de inspiração para a carreira acadêmica. Por estimular a comunicação e a didática, o projeto contribui para a formação de possíveis 
novos docentes. CARDOSO et al. (2014) reforçam a importância de atuar com esses aspectos na formação de professores na área de nutrição.

A pós-produção dos vídeos requer o emprego de programas de edição específicos, como o Windows Movie Maker, e também o uso de softwares usuais de maneiras não exploradas, como o Microsoft Power Point. Assim, amplia-se o horizonte de ferramentas que o aluno pode utilizar durante a graduação. A participação no projeto colocou os graduandos em contato com ambientes pouco explorados na universidade, como o estúdio de gravação, permitindo um melhor aproveitamento de tais espaços. O sucesso da experiência pode ser observado em discurso obtido durante as entrevistas com os alunos:

Além de somar mais um projeto na carreira, fazer parte da equipe USParódia fez com que todo o meu desempenho em outras atividades da graduação se tornasse mais criativo. $\mathrm{O}$ medo de experimentar novos programas para realização de trabalhos ou o receio de inovar ficaram para trás e passaram a fazer parte do cotidiano.

BANDUK et al. (2009), em um estudo sobre identidade profissional, ressaltam que o nutricionista é um educador. Assim, a contribuição do projeto USParódia para a formação do nutricionista é importante, uma vez que incentiva a educação de maneira inovadora e atual. Paralelamente, a promoção da educação nutricional por meio de vídeos na internet confere destaque ao amplo trabalho do nutricionista, sobretudo quando se considera que as diretrizes curriculares dos cursos de nutrição, em geral, não abrangem a comunicação audiovisual (SOARES \& AGUIAR, 2010).

$\mathrm{O}$ uso da internet como uma colaboradora no ensino universitário tem se mostrado benéfico em diferentes áreas do ensino em saúde, pois promove uma aproximação da universidade com o público, promovendo uma maior identificação deste com o ambiente de ensino (LOBO, 2015; SILVA et al., 2015; SILVEIRA et al., 2015; SHÜTZEL et al., 2012).

\section{Conclusão}

O projeto USParódia é enriquecedor bilateralmente, uma vez que promove a expansão da formação dos alunos que participam da equipe do projeto, no sentido de estimular o uso de novas tecnologias. Além do impacto dos vídeos produzidos, que tiveram um alcance de milhares de pessoas, número importante para a promoção da saúde. Acredita-se essencial a continuidade do projeto na graduação em Nutrição na Faculdade de Saúde Pública e, talvez, possa ser expandido para outros cursos.

\section{Referências Bibliográficas}

ABEDIN, Tasnima; AHMED, S; AL MAMUN, M; AHMED, S. W.; NEWAZ, S; RUMANA, N.; TURIN, T. "YouTube as a Source of Useful Information on Diabetes Foot Care". Diabetes Research and Clinical Practice, vol. 110, n. 1, 2015, pp. e1-e4.

BANDUK, Maria Luiza Sampaio; RUIZ-MORENO, L; BATISTA, N. A. "A Construção da Identidade Profissional na Graduação do Nutricionista". Interface - Comunicasãa Saúde Educaşão, vol. 13, n. 28, 2009, pp. 111-120.

BOOG, Maria Cristina Faber; VIEIRA, C. M.; OLIVEIRA, N. L.; FONSECA, O; LABBATE, S. "Utilização de Vídeo como Estratégia de Educação Nutricional para Adolescentes: Comer... O Fruto ou o Produto?". Revista de Nutrição, vol. 16, n. 3, 2003, pp. 281-293.

CARDOSO, Cléia Graziele Lima do Valle; SILVA, A.S.; VARGAS, G. J.; PASSOS, X. S. "O Papel dos Docentes na Formação de Novos Professores de Nutrição". Revista Brasileira de Educaşão Médica, vol. 38, n. 3, 2014, pp. 367-371.

DUNCAN, Ian; YARWOOD-ROSS, L; HAIGH, C. "YouTube as a Source of Clinical Skills Education". Nurse Education Today, vol. 33, 2015, pp. 1576-1580.

GOMES, Romeu; SOUZA, E. R.; MINAYO, M. C. S.; MALAQUIAS, J. V.; SILVA, G. F. R. "Organização, Processamento, Análise e Interpretação de Dados: o Desafio da Triangulação". In: MINAYO, M. C. S.; ASSIS, S. G.; SOUZA, E. R. Avaliação por Triangulacão de Métodos: Abordagem de Programas Sociais. Rio de Janeiro: Editora Fiocruz, 2005, pp. 185-221.

LOBO, Luiz Carlos. "Educação Médica nos Tempos Modernos". Revista Brasileira de Educaşão Médica, vol. 39, n. 2, 2015, pp. 328-332.

REGINE, Elisabetta; GOMES, R. C. F.; FAGUNDES, A. A.; PINHEIRO, A. R. O.; TEIXEIRA, B. A.; SOUZA, J. S.; TORAL, N.; MONTEIRO, R. A. "A Formação em Saúde Pública nos Cursos de Graduação de Nutrição no Brasil". 
Revista de Nutrição, vol. 25, n. 1, 2012, pp. 21-33.

SHÜTZEL, Manuel; RODRIGUES, C. J. S.; DUMONT; S. M.; PARISOTTO, V. S. "Projeto Imagem da Semana". Revista Brasileira de Educação Médica, vol. 36, n. 3, 2012, pp. 423-430.

SILVA, J. R.; MEDEIROS, F. B.; MOURA, F. M. S.; BESSA, W. S.; BEZERRA, E. L. M. "Uso das Tecnologias de Informação e Comunicação no Curso de Medicina da UFRN". Revista Brasileira de Educação Médica, vol. 39, n. 4, 2015, pp. 537-541.
SILVEIRA, João Luiz Gurgel Calvet; RODRIGUES, K. F.; SHISHIDO, M.; MORAES, P. "Pesquisa e Extensão em Saúde e a Aprendizagem nos Níveis Cognitivo e Afetivo". Revista Brasileira de Educasão Médica, vol. 39, n. 4, 2015, pp. 550-557.

SOARES, Nadia Tavares; AGUIAR, A. C. "Diretrizes Curriculares Nacionais para os Cursos de Nutrição: Avanços, Lacunas, Ambiguidades e Perspectivas". Revista de Nutrição, vol. 23, n. 5, 2010, pp. 895-905.

Publicado em 05/07/2016.

\section{Anexo 1}

Vídeos produzidos e que obtiveram maior receptividade (mais de nove mil visualizações).

\begin{tabular}{llll}
\hline Paródia & Música original & Artista & Link \\
\hline Comi mais frutas & I Kissed a Girl & Katy Perry & https://goo.gl//fVpkg \\
Show das leguminosas & Show das Poderosas & Anitta & https://goo.gl/QDdwUy \\
Então é Natal & Então é Natal & Simone & https://goo.gl/CrUhkK \\
Presa estou & Let it Go & Disney (Frozen) & https://goo.gl/1YsjnM \\
\hline
\end{tabular}


